\title{
Application of Outward Bound in Traditional Sports Teaching of Minority in China
}

\author{
Li Qin, Shubing Zhang \\ Nanchang Institute of Science \& Technology, Nanchang City, Jiangxi \\ Province, 330108, China
}

\begin{abstract}
Minority sports have a unique cultural charm, and they have gradually become the regular content of many college physical education classes. Outward bound is conducive to improving the quality of college students, and promoting their allround development. Besides, its teaching mode has been recognized and loved by the majority of students. In this paper, based on the authors' learning and practical experience, we first analyzed the feasibility of the combination of minorities' sports and outward bound, and then put forward the method of applying the outward bound in physical education teaching. The research results in this paper have certain positive significance for the optimization of minorities' traditional sports teaching.

Keywords: Minority in China; traditional sports; outward bound; feasibility; business strategy
\end{abstract}

\section{Introduction}

With the social development and education system reform, more and more attention has been paid to physical education in school education. Some schools even offer special courses for students with sports specialty so that they can get professional training. Outward bound is a scientific and efficient method of physical training, in which the targeted training is conducted mainly based on students' characteristics, and students can temper their wills, build up their bodies, improve their psychological quality, and cultivate a positive attitude towards life by creating representative scenes and exercise methods[1]. Therefore, the application of outward bound in physical education teaching has been widely concerned, and the application method of outward bound has also received much 
attention.

\section{Comparison between College National Physical Education and Outward bound, and the Feasibility Analysis of their Combination}

\subsection{Similarity of teaching content}

As a kind of experiential training, the outward bound emphasizes the physical participation and sensory experience. Its action details can be deconstructed into limb movements, and can be measured from five indicators including the heart and lung endurance, muscle strength and muscle endurance, body composition, softness and neuromuscular relaxation. Many national traditional sports are the recreational activities of the national people in the spare time. Outward bound items often allow participants to develop a strong interest in the process of experience and breakthrough, and to be fully engaged. Many outward bound items themselves are full of fun, which allow students quickly enter the training state in a joyful atmosphere[2].

\subsection{Consistency of teaching objectives}

The national sports items are based on physical exercise. Participants are subjected to a certain physiological load in the movement with physical and mental pleasure, which helps the body's functional form, physique and physical fitness develop in a healthier direction. Besides, they can effectively regulate people's psychology, which is conducive to improving the contemporary college students' physical and mental health level. This corresponds to the "physical health goals" and "motor skill goals" in the college physical education curriculums. At the same time, the national traditional sports are characterized by fitness, entertainment and interestingness, and have rich content and various forms, which can win people's love, and make them continue to operate and exercise[3]. In addition, many traditional items without space constraints have simple rules, and are easy to operate, which provides the conditions for people to widely carry out and participate in the exercise. This corresponds to the "campaign participation goal". Most of national traditional sports are group items. This reflects the national traditional sports have the connotation and value of cultivating team spirit and enhancing the unity and cooperation ability. This corresponds to "social adaptation goals".

\subsection{Referentibility of teaching methods}

National traditional sports teaching has not only the characteristics of general physical education teaching, but also their own independent characteristics. The book named "An Introduction to National Traditional Sports", which is edited by Zhang Xuanhui, summarizes four teaching principles, which include the principle 
of collective cooperation. This corresponds to another important feature namely teamwork of college outward bound items. Most outward bound items need team collaboration. Currently, most national sports teaching use the western competitive sports teaching methods, in which many problemsexist. Many scholars have carried out the pertinent research on the national traditional sports teaching methods. We hold that the teaching method of outward bound is also a breakthrough point which is worth exploring.

The teaching mode of outward bound has inherited the core process of experiential teaching. This teaching mode is students-oriented, which emphasizes students' participation and independent experience. At the same time, it attaches great importance to the reflection and share after the experience. The efforts at the stage of reflection and share can make the experience not become formalistic, promote the clarification of learning outcomes such as knowledge, behavior and emotional attitude, and strengthen the study effect[4]. If the national traditional sports can be effectively combined with outward bound, it can enable students to more deeply understand the implication of deep meaning of the items, and deepen the understanding of the related knowledge and cultural background of national traditional sports.

\section{Methods of Application of Outward Bound in Physical Education Teaching}

\subsection{Scenario simulation method}

Scenario simulation refers to the method that the teachers set up items through the specific scene content in the process of teaching to enable students to conduct scenario simulation. Due to condition limitations and for security considerations, the students have less opportunities for outdoor outward bound in schools. Therefore, teachers can use the scenario simulation method in the application of outward bound in physical eduction teaching. Assuming that students conduct outward bound in a specific outdoor scene, the scene can be arranged through the props in order to improve the enthusiasm and initiative of students to exercise, and make them participate in the activities.

\subsection{Experiential learning method}

Experiential learning is the most basic form of learning for students, which enables students to understand the nature of things in the activity according to their own personal experience through repeated observation, practice and exercise. The learned skills and the developed habits in the activities have a certain impact on their own character and habits, and even values and outlook on life[5]. Therefore, the application of outward bound in physical education teaching can be carried out through the experiential learning method, which enables students to personally participate in the challenges and obtain self-breakthrough. Besides, the students can not only learn the skills of physical exercise and basic outdoor 
survival skills in the process of outward bound, but also exercise their firm will, form good habits, and improve teamwork awareness.

Experiential learning is a commonly used method in outward bound, which enables the students be in outdoor activities, perform the real experience, and bring the effect of outward bound into full play. For example, in the physical education teaching in conditioned school, the teacher can organize students to conduct rock climbing activities in a special climbing training base, complete the independent climbing, personally experience climbing skills and the process of rock climbing, and exercise their will power.

\subsection{Cooperative learning method}

Cooperative learning is an effective way to cultivate students' team cooperation ability, which enables the students to achieve their goals through cooperation in the process of practice. The application of outward bound in physical education teaching can be carried out through cooperative teaching methods. The teachers set up activities, and then the students communicate with each other to find the right way to complete the activities through cooperation, which enables the students to understand the importance of teamwork, improve their teamwork awareness, and also exercise their individual ability[6].

\subsection{Inquiry learning method}

Inquiry learning is the method that, under the guidance of scientific theory, the students use scientific methods to explore and research, acquire knowledge, improve skills and expand thought based on their active participation according to their own conjecture or hypothesis. Inquiry learning is an effective way of learning. As an important course to improve the students' physical quality and cultivate their team cooperation consciousness, physical education teaching has important influence on the students' personal development. The teachers can use the method of inquiry learning in the application of outward bound in physical education so that the students can actively explore the problem-solving method in outward bound, which enables the students not only to get physical exercise and cultivate sense of teamwork, but also to bring their subjective initiative into full play and expand their thought in the process of outward bound.

\subsection{Self-evaluation method}

If the task is not completed, the students first think of the errors from a member of the team, and rarely think of their own mistakes in the process of teamwork, which results in mutual blame and suspicion among team members. Selfevaluation method can enable students to conduct correct evaluation on themselves in practice, recognize their own shortcomings and mistakes in the activities, learn to find the reasons from themselves, and thus actively correct themselves and make contributions for the team. In the application of outward bound in physical education teaching, the teachers can enable the students to conduct the correct self-evaluation through the games, find out their own 
deficiencies, actively take the initiative to correct the errors, improve their teamwork skills, and develop self-examination habits[7]. For example, the teachers can conduct "Eyebrow-level Staff" game in the process of physical education teaching. Its specific game method is: divide all students into two teams, face to face stand together, and put a three-meter long stick on the ground with only one finger. If the finger leaves the stick, he fails. This is a full test of the teamwork ability of the students. If one fails in the game, the goal cannot be completed. Therefore, each participant needs to take it seriously. When the game fails, one should find out their own reasons. They should obey the commands, cooperate with each other, and complete the game together.

\section{Conclusion}

With the development of society and the reform of educational system, outward bound, as an effective sports training item, has been widely used by some enterprises in the daily physical exercise of employees, and also went gradually into the campus, which is widely used in the school physical education teaching. Physical education class, an important course for students to exercise after cultural courses, is loved by the students. The application of outward bound in physical education is also popular among students. However, the teachers often cannot perform the physical education teaching activities according to students' learning characteristics, makes the outward bound lose its original meaning. Therefore, in the process of applyiny outward bound to physical education teaching, the teachers should perform the teaching activities according to the teaching conditions and students' characteristics, enable them to find out the right methods such as scenario simulation, cooperative learning, inquiry learning and self-evaluation, which make the students to exercise in outward bound, improve their teamwork capabilities, and bring the effect of outward bound in physical education teaching into full play.

\section{References}

[1] WANG Chen. Analysis of the outward bound application methods in physical education teaching. Shandong Social Sciences, (01), pp.336-337, 2016.

[2] LIU Wei. Analysis of the application of outward bound in physical education teaching. Contemporary Sports Technology, (35), pp.27-28, 2015.

[3] WANG Chengjian. Analysis of the application of outward bound mode in college physical education teaching. Journal of Jilin Province Education Institutes (Midmonth), (07), pp.102-103, 2012.

[4] LIU Xilun. The feasibility analysis of the combination of national traditional sports with outward bound. Journal of Taiyuan Urban Occupational Technology Institutes, (10), pp.173-174, 2011.

[5] GU Hongwei, HUANG Yutao. Application of outward bound in college 
physical education. Journal of Harbin Physical Education Institutes, (03), pp.7274, 2010.

[6] XI Yanhui, HONG Yunmin, LV Xianbo, DONG Kongmei. Application and research on outward bound in college physical education. Sports Science and Technology Bulletin, (08), pp.10-11, 2007.

[7] WANG Danxia, XIE Qiying, LUO Ling, WANG Youzhi, LI Chunhua. Research on mental outward bound of physical education teaching in national college. Journal of Qinnan National Normal Institutes, (06), pp.82-84, 2006. 